Old Dominion University

ODU Digital Commons

\title{
Abnormal Response of Costal Chondrocytes to Acidosis in Patients with Chest Wall Deformity
}

\author{
A. Asmar \\ Old Dominion University, aasma002@odu.edu \\ Iurii Semenov \\ Old Dominion University, isemenov@odu.edu \\ R. Kelly Jr. \\ Eastern Virginia Medical School \\ Michael Stacey \\ Old Dominion University, mstacey@odu.edu
}

Follow this and additional works at: https://digitalcommons.odu.edu/bioelectrics_pubs

Part of the Cells Commons, Genetic Phenomena Commons, and the Musculoskeletal System Commons

\section{Original Publication Citation}

Asmar, A., Semenov, I., Kelly, R., \& Stacey, M. (2019). Abnormal response of costal chondrocytes to acidosis in patients with chest wall deformity. Experimental and Molecular Pathology, 106, 27-33. https://doi.org/10.1016/j.yexmp.2018.11.011 


\title{
Abnormal response of costal chondrocytes to acidosis in patients with chest wall deformity
}

\author{
A. Asmar ${ }^{\mathrm{a}}$, I. Semenov ${ }^{\mathrm{a}}$, R. Kelly Jr ${ }^{\mathrm{b}}$, M. Stacey ${ }^{\mathrm{a}, *}$ \\ ${ }^{a}$ Frank Reidy Research Center for Bioelectrics, Old Dominion University, Norfolk, VA, USA \\ ${ }^{\mathrm{b}}$ Department of Surgery, Eastern Virginia Medical School, Pediatric Surgery Division, Children's Hospital of the King's Daughters, Norfolk, VA, USA
}

\section{A R T I C L E I N F O}

\section{Keywords:}

Cartilage

Chondrocytes

Ion channels

\section{Calcium}

Pectus carinatum

Pectus excavatum

\begin{abstract}
A B S T R A C T
Costal cartilage is much understudied compared to the load bearing cartilages. Abnormally grown costal cartilages are associated with the inherited chest wall deformities pectus excavatum and pectus carinatum resulting in sunken or pigeon chest respectively. A lack of understanding of the ultrastructural and molecular biology properties of costal cartilage is a major confounder in predicting causes and outcomes of these disorders. Due to the avascular nature of cartilage, chondrocytes metabolize glycolytically, producing an acidic environment. During physical activity hydrogen ions move within cartilage driven by compressive forces, thus at any one time, chondrocytes experience transient changes in $\mathrm{pH}$. A variety of ion channels on chondrocytes plasma membrane equip them to function in the rapidly changing conditions they experience. In this paper we describe reduced expression of the ASIC2 gene encoding the acid sensing ion channel isoform 2 (previously referred to as ACCN1 or ACCN) in patients with chest wall deformities. We hypothesized that chondrocytes from these patients cannot respond normally to changes in $\mathrm{pH}$ that are an integral part of the biology of this tissue. Activation of ASICs indirectly creates a cascade ultimately dependent on intracellular calcium transients. The objective of this paper was to compare internal calcium signaling in response to external $\mathrm{pH}$ changes in costal chondrocytes from patients with chest wall deformities and healthy individuals. Although the molecular mechanism through which chondrocytes are regulated by acidosis remains unknown, we observed reduced amplitudes of calcium rise in patient chondrocytes exposed to low $\mathrm{pH}$ that become further impaired upon repeat exposure.
\end{abstract}

\section{Introduction}

Chest wall deformities (CWD) are significant disorders of costal cartilage and a leading health problem affecting young adults. CWD patients are often described as having 'weak' cartilage and typically face exercise intolerance due to associated heart and lung limitations, in addition to substantial psychosocial problems in a vulnerable age group (Kelly Jr. et al., 2013). In severe cases where access to proper reparative surgery is unavailable, marked functional consequences may be encountered. CWD are a complex inherited disorder affecting 1 in 400 to 1 in 1000 individuals, primarily males ( 4M:1F) (Creswick et al., 2006; Horth et al., 2012) and can be divided into those with sunken chests (pectus excavatum, PE) and those with pigeon chests (pectus carinatum, PC). Repair of PE is now routinely performed following the minimally invasive Nuss procedure (Nuss, 2008, Pilegaard and Licht, 2017) where one or two substernal support titanium bars are inserted and kept in place for approximately 2-3 years. Outcomes are reported as excellent (Goretsky et al., 2004). With the introduction of stabilizers, bar displacements dropped significantly. Safety concerns regarding the absorption of electro-magnetic (EM) energy (specific energy absorption rate; SAR) by the implanted bar arose due to the length of time the bars are in place. This was addressed by Miaskowski et al. (2016) whose results clearly indicated that a conductive object, such as a concave implant may cause possible local enhancement of power absorption and produce characteristic SAR peaks around the bar-implant. However, the obtained maximum SAR values did not exceed the recommended reference levels for environmental and occupational exposures.

Chondrocytes, the cartilage forming cells, reside under an environment that is toxic to most cell types due to a lack of vasculature, persistent hypoxia, and related acid production through glycolytic metabolism. In other cell types low $\mathrm{pH}$ activates a unique family of membrane ion channels; the acid-sensing ion channels (ASICs) (Chu et al., 2011). In pathological conditions of articular cartilage such as osteoarthritis and rheumatoid arthritis, the tissue $\mathrm{pH}$ become acidic, falling to approximately pH 5.5 (Hu et al., 2012). In this paper we describe reduced expression of the ASIC2 gene in patients with chest wall

\footnotetext{
* Corresponding author at: Frank Reidy Research Center for Bioelectrics, 4211 Monarch Way, Suite 300, Norfolk, VA 23508, USA.

E-mail address: mstacey@odu.edu (M. Stacey).
} 
deformities. We hypothesized that chondrocytes from these patients exhibit an abnormal response to changes in external $\mathrm{pH}$ that are experienced as an integral part of the biology of this tissue. Activation of ASICs typically creates a cascade ultimately dependent on the formation of intracellular calcium transients. Changes in intracellular calcium signaling cause downstream changes in gene expression. An excessive amount of intracellular calcium induces cell death through apoptosis in chondrocytes (Rong et al., 2012; Li et al., 2014; Zhou et al., 2015). Low $\mathrm{pH}$ is known to cause a decrease in extra cellular matrix (ECM) production (Yuan et al., 2010). The objective of this study was to measure intracellular calcium changes in response to reducing environmental $\mathrm{pH}$ around costal chondrocytes from patients with CWD.

\section{Methods}

\subsection{Patients}

Human costal cartilage was obtained from three patients with pectus carinatum and three with pectus excavatum, all severe enough to warrant surgical repair. Informed consent was obtained following IRB approval of the protocol at Eastern Virginia Medical School and Old Dominion University. The IRB protocol currently prevents disclosure of many clinical features, and thus close correlation of clinical phenotype with gene expression is not possible. Costal cartilage samples were collected from ribs 6-8 at surgery. Experiments were performed on the round, rod-like, midsections of cartilage. All patients were male, with an age range of early teen to early 20 's. Apparently normal costal cartilage was obtained from three age-matched-controls, one 15 year old and two 17-year-old males, and processed within $24 \mathrm{~h}$. Cells were cultured in Chondrocyte growth medium (PromoCell) at $37^{\circ} \mathrm{C}$ with $5 \%$ $\mathrm{CO}_{2}$ in humidified air. Chondrocytes were maintained in suspension culture (Bosnakovski et al., 2004; Wa et al., 2015) to maintain their differentiated phenotype, and briefly expanded in tissue culture flasks before plating onto $10 \mathrm{~mm}$ diameter glass coverslips. All experiments used cells that had been passaged $<4$ times.

\section{2. $R N A$ isolation and real time $q P C R$}

RNA was directly isolated from cells in tissue culture dishes, and genomic DNA eliminated using a Direct-zol ${ }^{\mathrm{TM}}$ RNA MiniPrep (Zymo Research, Irvine, CA, USA). Complimentary DNA (cDNA) was generated using an RT-First Strand Kit (Qiagen, Valencia, CA, USA). RNA and cDNA concentrations were measured by NanoDrop (Thermo Fisher). Polymerase chain reactions (PCRs) were performed using SYBR green detection (Qiagen) and customized ion channel array plates (Qiagen) in a BioRad CFX96 system (BioRad, Hercules, CA, USA). Manufacturer guidelines were used for PCR reaction volumes and cycle parameters. The cycling parameters were $95^{\circ} \mathrm{C}$ for $10 \mathrm{~min}$, then 40 cycles of $95^{\circ} \mathrm{C}$ for $15 \mathrm{~s}$ and $60^{\circ} \mathrm{C}$ for $60 \mathrm{~s}$. Reaction specificities were assessed with a melt curve of $65^{\circ} \mathrm{C}$ to $95^{\circ} \mathrm{C}$ in $0.2^{\circ} \mathrm{C}$ increments. Data was standardized to five reference genes defined in Fig. 1 (ACTB, B2M, GAPDH, HPRT1 and $R P L P O$ ) using the $\triangle \mathrm{Cq}$ method. All experiments were in triplicate and performed with positive and negative controls. At least two independent extractions were included. Gene expression was calculated as $2^{-\left(\mathrm{Cq}_{\mathrm{GOI}}-\mathrm{Cq}_{\mathrm{Ref}}\right)}$ where $\mathrm{Cq}_{\mathrm{GOI}}$ is the $\mathrm{Cq}$ value of the gene of interest, and $\mathrm{Cq}_{\text {Ref }}$, is the $\mathrm{Cq}$ value for the averaged reference genes. The assay range using the $\mathrm{RT}^{2}$ profiler array (Qiagen) is 6.8-35 Cq. In order to minimize the possibility of false-positives and account for variability, a constant concentration of total cDNA was used in all reactions and a raw $\mathrm{Cq}$ cutoff of 30 was used (Canales et al., 2006; Arikawa et al., 2008). Expression of the acid sensitive G-protein coupled receptor gene GPR68 (G Protein-Coupled Receptor 68) was also assessed using commercially available primers from Qiagen. Chondrocyte phenotype was confirmed by aggrecan $(A C A N)$, biglycan $(B G N)$, decorin $(D C N)$, and cartilage oligomeric matrix protein (COMP), gene expression by RT-PCR using commercially available primers (Qiagen).

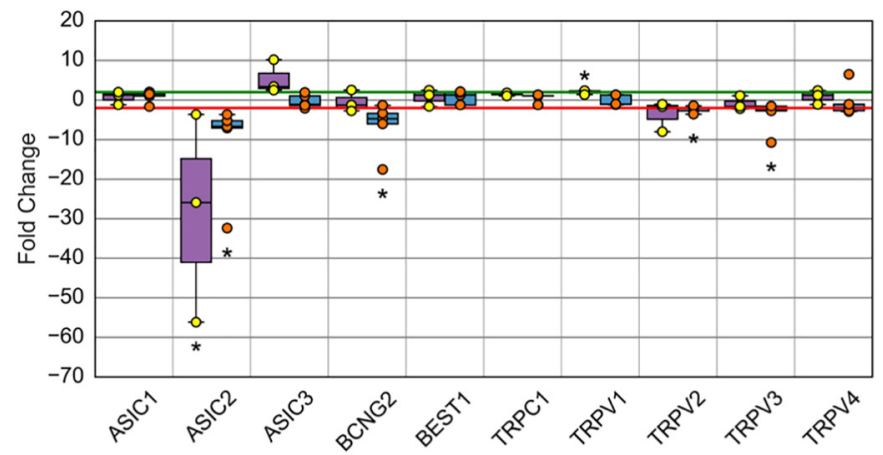

Fig. 1. Median fold changes in non-selective ion channels in chondrocytes of CWD patients using qPCR. Pectus excavatum (PE; purple box plot) and pectus carinatum (PC; blue box plot) are shown relative to normal costal cartilage. Each sample was analyzed with an $n=3$ and significant changes $(p<.05)$ relative to normal costal cartilage are indicated $\left(^{*}\right)$. The green and red horizontal lines indicated a +2 or -2 fold change, respectively. Outlying data points in PC patients are indicated by unconnected orange dots. Genes analyzed are ASIC1, 2, and 3 Acid Sensing Ion Channel unit 1, 2, and 3; BCNG2 (HCN2) Hyperpolarization Activated Cyclic Nucleotide Gated Potassium and Sodium Channel 2; BEST1 Bestrophin; TRPC1 Transient Receptor Potential Cation Channel Subfamily C Member 1; TRPV1-4 Transient Receptor Potential Cation Channel Subfamily V Members 1-4. (For interpretation of the references to colour in this figure legend, the reader is referred to the web version of this article.)

\subsection{Protein extraction and ELISA}

Protein was isolated from chondrocytes grown in 3D as cell pellets by rinsing the cells in cold PBS three times, centrifuged at $300 \times g$ for $10 \mathrm{~min}$ at $4{ }^{\circ} \mathrm{C}$. RIPA buffer (Sigma) with protease inhibitors (Roche) was added for $10 \mathrm{~min}$ on ice to lyse cells and extract protein. The RIPAcell mixture was transferred to a conical tube with a $0.1-0.6 \mathrm{~mm}$ bead, loaded in a TissueLyser bullet blender (Qiagen) and run at $20-30 \mathrm{~Hz}$ for $2 \mathrm{~min}$. The homogenate was centrifuged at $14,000 \times \mathrm{g}$ for $15 \mathrm{~min}$ at $4{ }^{\circ} \mathrm{C}$ and the supernatant used for protein analysis. Total protein extract was quantified using a Bradford assay and ASIC2 determined by ELISA (a human ASIC2 monoclonal antibody detected by a biotin labeled polyclonal secondary antibody and measured colorimetrically via avidin/ peroxidase conjugates using a Molecular Devices Spectra-Max i3 plate reader) by comparing samples to an ASIC2 standard curve following manufacturer's guidelines (MyBioSource San Diego CA).

\subsection{Calcium imaging}

Intracellular calcium imaging was performed on control and a PC patient chondrocytes using procedures previously described (Semenov et al., 2013). Cells were cultured on glass coverslips, loaded with Fura2/AM dye (Sigma-Aldrich, St. Louis, MO, USA), and placed into a vacuum perfusion chamber mounted on an IX71 microscope (Olympus, Center Valley, PA, USA) while being maintained using a physiological solution consisting of $5.4 \mathrm{mM} \mathrm{KCl}, 140 \mathrm{mM} \mathrm{NaCl}, 2 \mathrm{mM} \mathrm{CaCl}_{2}, 1.5 \mathrm{mM}$ $\mathrm{MgCl}_{2}, 10 \mathrm{mM}$ glucose, and $5 \mathrm{mM}$ HEPES. Normal $\mathrm{pH}$ (pH 7.4) and low $\mathrm{pH}$ ( $\mathrm{pH}$ 5.5) physiological solutions were used. Cells were recorded in normal $\mathrm{pH}$ solution for $60 \mathrm{~s}$ and then perfused with low $\mathrm{pH}$ solution. After 3 min low $\mathrm{pH}$ solution was replaced with normal $\mathrm{pH}$ solution. Alternating excitation at 340 and $380 \mathrm{~nm}$ was provided with a xenon lamp using a Lambda DG4 switcher (Sutter, Novato, CA, USA), emission at $510 \mathrm{~nm}$ was collected via a UApoN340 $40 \times / 1.35$ objective (Olympus America, Center Valley, PA) and recorded with a iXon Ultra 897 electron multiplication CCD digital camera (Andor Technology, Belfast, UK). The intracellular calcium concentration was calculated using a calibration kit (Life Technologies, Carlsbad, CA, USA) and the equation: 
$\left[\mathrm{Ca}^{2+}\right]_{\mathrm{i}}=\left(\frac{R-R_{\min }}{R_{\max }-R}\right) \times K_{\mathrm{D}} \times \beta$

where $\left[\mathrm{Ca}^{2+}\right]_{\mathrm{i}}$ refers to internal calcium concentration and the recorded ratios are $R$, zero calcium ratio is $R_{\min }$, ratio at calcium saturation is $R_{\max }$, the effective dissociation constant is $K_{\mathrm{D}}$, and the ratio of free to bound dye is $\beta$ (Grynkiewicz et al., 1985).

\subsection{Metabolic activity}

Metabolic activity of cells was evaluated using an MTT (3-(4,5-dimethylthiazol-2-yl)-2,5-diphenyltetrazolium bromide) Cell Proliferation Assay Kit (ATCC) following manufacturer guidelines. The reduction of tetrazolium by metabolically active cells was quantified spectrophotometrically at 570-650 nm. Cells from two controls (C-08 and C-10), two PC patients (PC16 and PC34), and two PE patients (PE01 and PE02) were cultured in 96-well plates, then treated with growth mediums at pH 5.5, 6.0, and 6.5 and evaluated at $0,5,10,30$, $60 \mathrm{~min}$, and $24 \mathrm{~h}$ prior to spectrophotometric analysis. Each replicate was measured three different times and data pooled for each control and patient sample.

\subsection{Statistical analysis}

Statistical analysis was performed using Student $t$-test to determine significance between sample and control means. For all tests, $p<.05$ indicated the difference as significant. The number of repeat experiments performed is $n$.

\section{Results}

\subsection{Expression of acid sensing ion channel genes}

Chondrocyte phenotype was confirmed through four structural genes of cartilage expressed in the differentiated chondrocyte (Stacey et al., 2012; Asmar et al., 2015). Cq values confirming expression of $A C A N, B G N, D C N$, and COMP are all below our conservative cut off value of Cq30 (Table 1).

Median changes in gene expression of non-selective ion channels in three PE samples and three PC samples versus three normal costal chondrocyte samples showed few statistically significant differences (Fig. 1). No significant down regulation was observed in PE samples except for the acid sensing ion channel gene ASIC2. ASIC2 was the only gene to be down regulated in both PE and PC samples ( -25.94 -fold, $p<.02$ and -6.71 -fold, $p<.01$ respectively). In PC samples, significant down regulation was also observed in TRPV2 $(-2.09$, $p<.001)$, TRPV3 $(-2.35, p<.03)$, BCNG2 $(-3.36, p<.04)$, and GPR68 $(-3.13, p<.002)$ compared to controls. ASIC3 up regulation was observed in $\mathrm{PE}$, however levels were not significant $(+5.35$, $p<.22$ ). No significant up regulation was observed in any patient samples compared to controls.

Table 1

Chondrocyte phenotype confirmation was determined by measuring gene expression $\mathrm{Cq}$ values of four genes expressed in the differentiated cell (ACAN, $B G N, D C N$, and COMP) and three housekeeping genes (GAPDH, ACTB and $B 2 M)$.

\begin{tabular}{lllll}
\hline Gene & $\begin{array}{l}\text { PC19 Cq } \\
\text { average }\end{array}$ & $\begin{array}{l}\text { PC16 Cq } \\
\text { average }\end{array}$ & $\begin{array}{l}\text { C-08 Cq } \\
\text { average }\end{array}$ & C-10 Cq average \\
\hline ACAN & 26.01 & 26.94 & 25.22 & 22.14 \\
$B G N$ & 28.74 & 27.73 & 23.19 & 26.03 \\
$D C N$ & 27.21 & 22.95 & 18.68 & 23.10 \\
COMP & 24.69 & N/A & 21.72 & 20.44 \\
GAPDH & 20.01 & 20.32 & 18.83 & 19.15 \\
ACTB & 16.76 & 20.62 & 18.33 & 18.15 \\
$B 2 M$ & 18.06 & N/A & 19.68 & 20.18 \\
\hline
\end{tabular}

\subsection{Protein expression of ASIC2}

ASIC2 protein was calculated from an ASIC2 standard curve for C08, C-10, and PC34 as 2.75, 1.01 , and $0.91 \mathrm{ng} / \mathrm{mL}$ respectively and expressed as a percentage of total protein for each sample (Table 2). Normalized to each control, protein levels of ASIC2 in PC34 were 67\% and $85 \%$ of C-08 and C-10 respectively; agreeing with the reduced expression profiles obtained in Fig. 1.

\subsection{Calcium transits following increased acidity}

The significant down regulation of the ASIC2 gene in both PE and PC samples led to the question of whether chondrocytes of CWD patients are desensitized to external acidosis. Using live cell ratiometric monitoring of intracellular calcium, measurements from chondrocytes of normal costal and PC patients were performed (Fig. 2). Comparison of transients from PC patient (PC16) and control (C-08) cells (Fig. 3) showed the transient began to form at around $68.09 \pm 10.23 \mathrm{~s}$ and peaked at $103.03 \pm 15.36 \mathrm{~s}$ in control cells $(n=8)$; while in PC16 cells, the transient began with a significant delay at $160.81 \pm 12.72 \mathrm{~s}$ and peaked at $200.54 \pm 2.32 \mathrm{~s}(n=3)$. Amplitudes of calcium transients also showed significant differences $(p<.05)$ in C-08 $(0.892 \pm 0.152 \mu \mathrm{M})$ as compared to PC16 cells $(0.715 \pm 0.0714 \mu \mathrm{M})$. Moreover, PC16 had significantly higher basal levels of intracellular calcium than control cells (PC16: $0.156 \pm 0.00747 \mu \mathrm{M}, \quad$ C-08: $0.121 \pm 0.00937 \mu \mathrm{M}, p<.01)$. Amplitudes of calcium release were consistently lower in patients, however the delayed onset of the calcium transit appeared not to be consistent finding.

\subsection{Response of patient chondrocytes following further exposure to acidity}

Patient (PC34) and control (C-10) cells were exposed to reduced $\mathrm{pH} 5.5$ followed by restoration to $\mathrm{pH} 7.4$ and then a second exposure to pH 5.5. Similar to PC16, there was a significant difference in amplitude of calcium release between control and patient cells when first exposed to pH $5.5(0.133 \mu \mathrm{M}$ compared to $0.0987 \mu \mathrm{M}, p<.005)$. Control cells showed near identical amplitudes of calcium release upon a second exposure to pH5.5 (Fig. 4. $0.133 \mu \mathrm{M}$ and $0.121 \mu \mathrm{M}$ respectively, $p<.32$ ) as compared to PC34, which showed a significant reduction in amplitude $(0.098 \mu \mathrm{M}$ and $0.051 \mu \mathrm{M}$ respectively, $p<.0001)$. Differences in amplitude of calcium release between control and patient samples were highly significant upon second exposure $(0.121 \mu \mathrm{M}$ compared to $0.051 \mu \mathrm{M}$ respectively, $p<.0001$ ).

\subsection{Calcium is released from internal stores}

In a single control sample (C-08) external $\mathrm{Ca}^{2+}$ was chelated with EGTA and cells exposed to a reduction of $\mathrm{pH}$ to 5.5. Fig. 5 shows an immediate increase in calcium concentration indicating release from internal stores. Interestingly, when external calcium was depleted the shape of the curves was not uniform, but rather showed two-step dynamic with fast initial rising followed by a slower increase towards the peak (Fig. 6). Results indicate the compound nature of $\mathrm{Ca}^{2+}$ increase as compared to one-step $\mathrm{Ca}^{2+}$ release from the endoplasmic reticulum (ER) (via RyR or IP3 receptors). This was not observed when external calcium was present.

\subsection{Metabolic activity of chondrocytes}

Cell metabolism was analyzed by the MTT assay in costal chondrocytes (C-08, C-10, and four different samples from CWD patients; PC16, PC34, PE01, and PE02) following acid challenge. Data was pooled for each sample type (Fig. 7). At pH 6.5 and 6.0, similar levels of cell metabolism were observed at almost all time points $(0,5,10,30$, $60 \mathrm{~min}$ and $24 \mathrm{~h}$ ). Unexpectedly, challenge with media at $\mathrm{pH} 5.5$ lead to consistent decreases in metabolism in both PC and PE cells, while 
Table 2

Reduced protein expression of ASIC2 in PC34 cells compared to controls.

\begin{tabular}{|c|c|c|c|c|}
\hline Sample & Total protein Conc mg/mL & ASIC2 conc ng/mL & ASIC2 expression $\%$ total protein & ASIC2 expression (PC) as a \% of each control \\
\hline C-08 & 18.88 & 2.75 & 0.014 & $100(67 \%)$ \\
\hline C-10 & 13.74 & 1.01 & 0.007 & $100(83 \%)$ \\
\hline PC34 & 15.76 & 0.91 & 0.0058 & \\
\hline
\end{tabular}

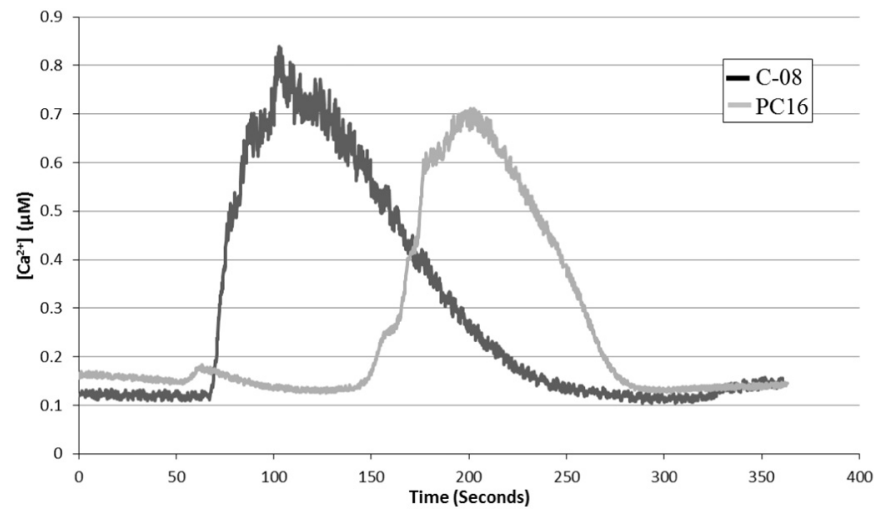

Fig. 2. Costal chondrocytes from a control (C-08) and a PC patient (PC16) were exposed to change of $\mathrm{pH}$ and ratiometric measurements of calcium release made. $\mathrm{pH}$ was changed from 7.4 to 5.5 at $60 \mathrm{~s}$ and calcium release plotted against time.

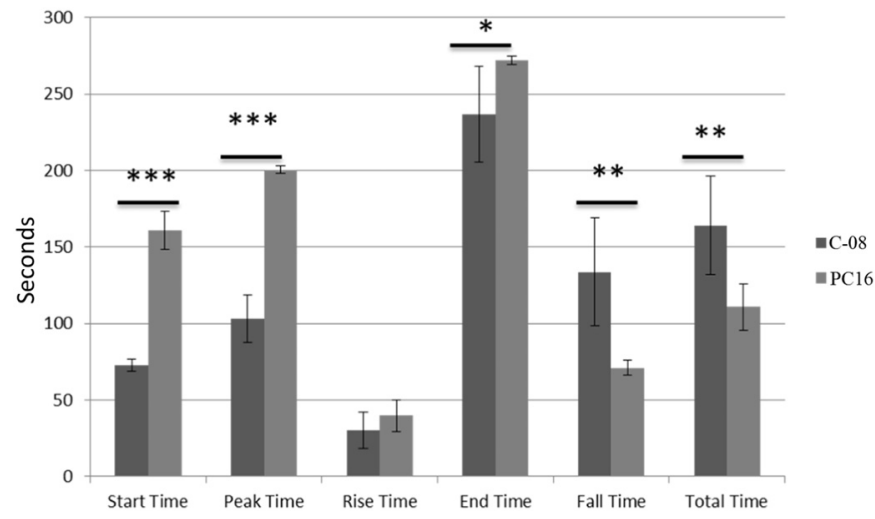

Fig. 3. Graphical display of intracellular calcium transient time properties following $\mathrm{pH}$ challenge in C-08 and PC16 chondrocytes. Significant differences $(p<.05,<0.01$, and $<0.001)$ are indicated by asterisks $\left(*, * *\right.$, and ${ }^{* * *}$, respectively).

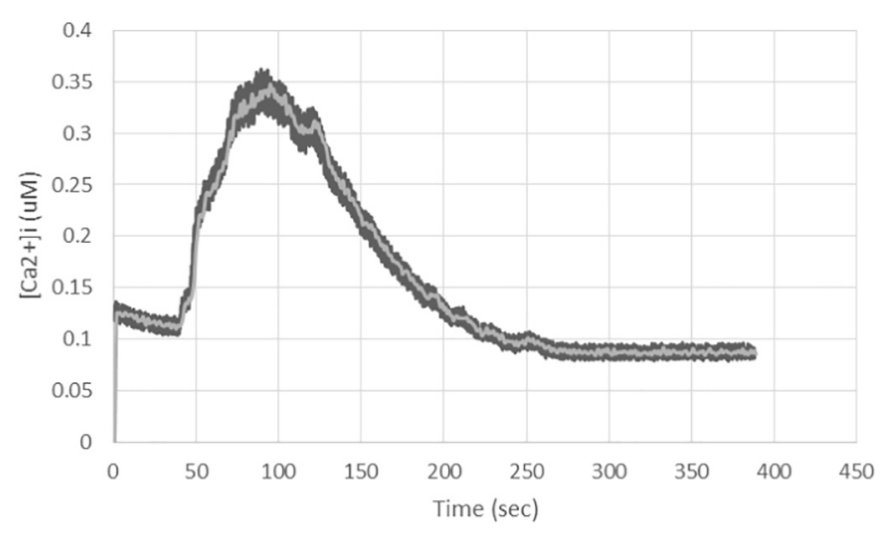

Fig. 5. Calcium is released from internal stores upon exposure to low $\mathrm{pH}$. Calcium release was measured in C-08 cells when the $\mathrm{pH}$ was reduced to 5.5 at 30 s. External calcium was chelated with EGTA.

control samples had a mixed response. The results show that the metabolic response by PC and PE cells may only be significant at $\mathrm{pH}<$ 6.0 .

\section{Discussion}

Costal cartilage is a much-understudied type of hyaline cartilage where deformities have significant clinical consequences. The spatial and temporal mechanical and electrochemical events in cartilage (Mow and Guo, 2002) led us to investigate the response of chondrocytes to their continually changing environment. The plasma membrane of a cell is the point where the cell directly interacts with its environment, and ion channels provide a conduit for cells to rapidly respond and maintain homeostasis specifically related to changes in $\mathrm{pH}$, osmolarity, and ionic concentrations (Stacey et al., 2014).

Channelopathies, pathologies with underlying defects in ion channel/transport, have been widely described in cell types known to possess a large number and diversity of ion channels, specifically in nerve and muscle. Chondrocytes also possess a large number and diversity of ion channels (Barrett-Jolley et al., 2010; Asmar et al., 2016). Although their functions are largely unknown in the environment in which this cell type resides, we posed the question as to whether this

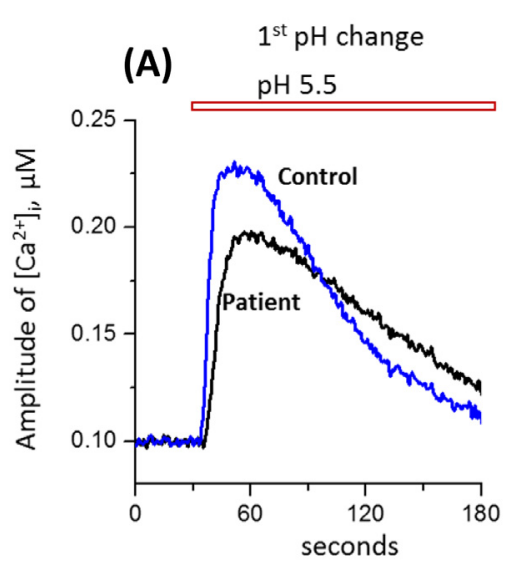

Fig. 4. Calcium release from patient and control cells following a second exposure to acidic $\mathrm{pH}$. (A) The $\mathrm{pH}$ was reduced to $\mathrm{pH} 5.5$ at $30 \mathrm{~s}$ and calcium release measured in PC34 and C-10 cells. (B) Cells were restored to $\mathrm{pH} 7.4$ and then changed for the second time to $\mathrm{pH}$ 5.5. Calcium release from patient cells were significantly lower than the first exposure $(p<0001)$. 


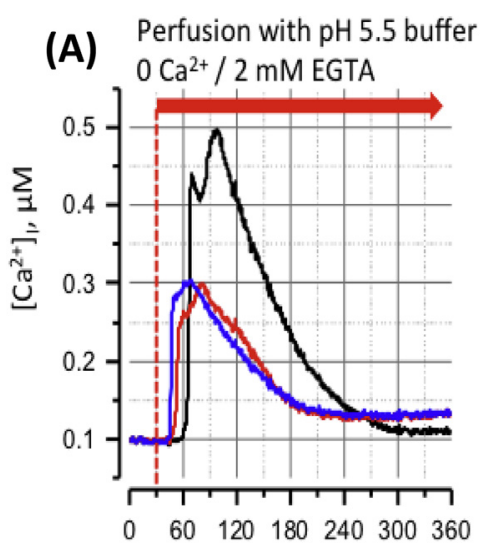

Time, $s$

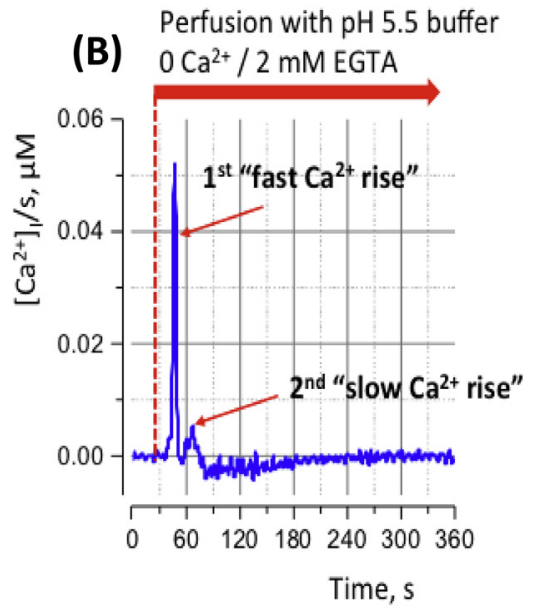

Fig. 6. (A) $\mathrm{Ca}^{2+}$-release from intracellular stores of three individual C-08 cells (black, red, and blue traces) upon perfusion with low $\mathrm{pH}$ (5.5) in zero $\mathrm{Ca}^{2+}$ solution (B) Dynamic of $\mathrm{Ca}^{2+}$ release from internal stores in zero $\mathrm{Ca}^{2+}$ solution. To distinguish components of compound $\mathrm{Ca}^{2+}$ release traces from (A) were shifted to the same point in the moment of initial $\mathrm{Ca}^{2+}$-rise differentiated and averaged. (B) show two speed components (fast and slow) in the dynamic release of $\mathrm{Ca}^{2+}$. (For interpretation of the references to colour in this figure legend, the reader is referred to the web version of this article.) tissue, hyaline cartilage, may also be susceptible to channel related pathologies. In this study we identified consistent down regulation of the acid sensing ion channel gene ASIC2 in patients with chest wall deformities.

Down regulation of ASIC genes are attributed to increased cell survival by prevention of acid-induced injury in rat articular chondrocytes. Acid-induced cell death in chondrocytes occurs through a mitochondrial-dependent pathway, and ASIC-induced calcium entry cause induction of caspase 3-mediated apoptosis (Hu et al., 2012). Rat articular chondrocytes show reduced cellular death using ASIC blockers during external acidosis (Rong et al., 2012). Although down regulation of ASICs is expected to increase cell viability under acidic $\mathrm{pH}$ stress, it also causes the cell to become more desensitized to extracellular acidosis. Shifts in $\mathrm{pH}$, which occur regularly in cartilage, are crucial to proper maintenance of this tissue, so desensitization could impair or modify its development and growth. Down regulation of ASIC2 gene in PC and PE samples led to the question of whether chondrocytes of CWD patients are desensitized to external acidosis.

We consistently observed reduced amplitude of response in patient samples to repeated exposure of acidic conditions suggesting normal homeostasis is not achieved. As a result, cell injury may occur, apparent through cell metabolism/cell death analysis. Cell metabolism by MTT assay in normal, PC, and PE costal chondrocytes following prolonged acid challenge at pH 6.5 and 6.0, showed very similar levels of cell metabolism at almost all time points. Challenge with media at $\mathrm{pH} 5.5$ lead to consistent decreases in metabolic activity in chondrocytes from PC and PE patients, while control samples had a mixed response. The response by chondrocytes from PC and PE patients and gradual response by control cells may be indicative of homeostatic pathways being immediately compromised in pectus-affected cells. This compromised response due to external acidosis at pH5.5 may trigger downstream signals that would otherwise be blocked by a consistent calcium transient formation.

Mechanistically, ASICs import calcium from the exterior of the cell and pathways do not appear to involve IP3 and RyR receptors, receptors of the ER involved in release of calcium from internal stores and formation of intracellular calcium transients. When external calcium was depleted, calcium transits were still observed, suggesting release from internal stores. However, the calcium release response appeared unusual in that the rise curve appears to have two components, "fast" and "slow", instead of a single fast rise time. This indicates two different mechanistic pathways may be responsible for internal calcium release. Release of calcium from internal stores mechanistically implicates IP3R, there are also three isoforms of the ryanodine receptor, RyR1-3. Our previous studies show that RyR3 gene was only expressed in fetal costal chondrocytes (Asmar et al., 2016), and we cannot presently assign a
(A)

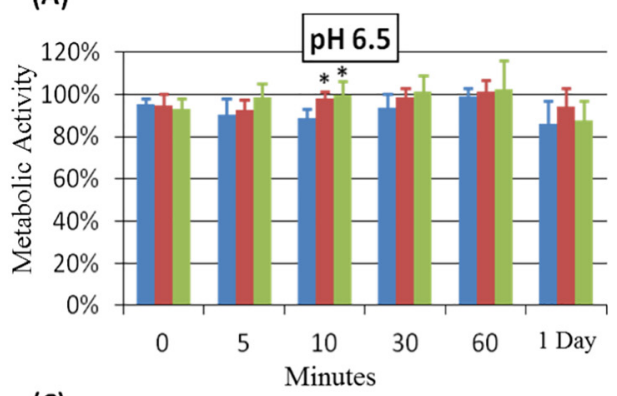

(C)

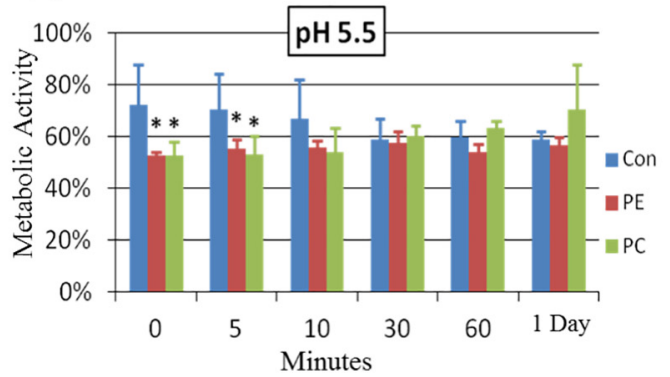

(B)

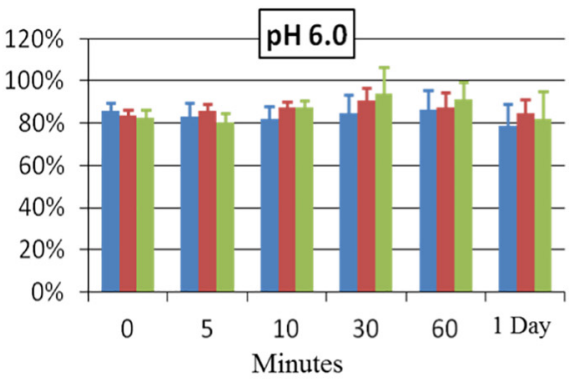

Fig. 7. Metabolic activity of costal chondrocytes were measured after being subject to low $\mathrm{pH}$ : (A) 6.5 , (B) 6.0 , and (C) 5.5, at several time points between control (blue), PC (green), and PE (red) cells. Metabolic activity levels displayed are compared to cells treated with normal media (y-axis) at each time point $(x$-axis). Significant differences $(p<.05)$ between control and both PC and PE are indicated (*). (For interpretation of the references to colour in this figure legend, the reader is referred to the web version of this article.) 
role for these genes. In our PC samples we identified a small but significant down regulation of the gene GPR68, a G-coupled protein receptor that is activated by protons $\left(\mathrm{H}^{+}\right)$, resulting in cleavage of PIP2 to DAG and IP3 and release of calcium from internal stores (Hu et al., 2017). Down regulation of the gene GPR68 may reduce enzymatic kinetics that delays the calcium response when chondrocytes are exposed to decreased pH. ASIC2 may have a separate role, possibly through cell membrane depolarization by $\mathrm{Na}^{+}$transport.

Intracellular calcium levels are not well characterized for $\mathrm{pH}$ response in chondrocytes with previous recordings of calcium transient levels mainly in response to hypo-osmotic stress showing inconsistent peak levels and total time of intracellular calcium transients (Dascalu et al., 1996; Edlich et al., 2001; Parvizi et al., 2002; Yellowley et al., 2002; Sanchez et al., 2003; Sanchez and Wilkins, 2004; Kurita et al., 2015). To our surprise, we observed a delayed formation of calcium transients in PC16 cells. More samples will need to be analyzed to determine whether there is patient-to-patient variation in time of response to acidic $\mathrm{pH}$.

Critical information missing in the literature is short-term temporal studies on cell responses to external acidosis. Although the hypoxic nature of cartilage creates a slightly acidic environment, it is the mechanical changes of the tissue that produce the low $\mathrm{pH}$ environments for short time periods. Analyzing the literature yields only studies monitoring chondrocyte response to external acidosis for time points > $1 \mathrm{~h}$ (Yuan et al., 2010; Rong et al., 2012; Collins et al., 2013; Li et al., 2014; Zhang et al., 2016). Many studies monitored changes over days, but none immediately following a $\mathrm{pH}$ challenge. Our data show that chondrocytes are able to immediately respond to fluxes in $\mathrm{pH}$, and that these responses are compromised in chondrocytes derived from patients with chest wall deformities.

There are a number of limitations to this study. Patients undergoing repair of CWD tend to be of late teens to early 20's in age and there can be difficulty in obtaining age-matched controls. Our controls derived from accidental deaths (e.g. car/climbing accidents) where there is no record of osteopathology. Additionally the study numbers are small, however statistical significance has been shown. We plan to improve this study with larger numbers that we are able to link directly to full clinical presentation. In conclusion, we have identified reduction in ASIC2 gene expression in costal chondrocytes from patients with chest wall deformity. We speculated that patient chondrocytes may show abnormal response to acidosis and were able to show that calcium transient amplitudes are reduced in patient chondrocytes. Reduced amplitude of $\mathrm{Ca}^{2+}$ response appeared to become exacerbated upon repeat exposure to acidosis. Calcium also appears to be released from internal stores as a two-step process. We believe that we have identified a biomarker for patients with chest wall deformities that may point to the underlying defect of this complex inherited disorder. Once genetic/ protein components to these pathways are identified then it is possible to think of a therapy and/or 'cure'. Manipulation of chondrocytes in fully differentiated cartilage will be difficult. Cartilage grown from mesenchymal stem cells can be genetically manipulated prior to differentiation into cartilage and will likely be a more fruitful approach compared to manipulation of a fully differentiated tissue. As a result of this study, the fields of ion channel function and calcium biology with respect to pediatric cartilaginous disorders have been opened that may have beneficial consequences in pathological and regenerative medicine.

\section{Acknowledgements}

Research reported in this publication was supported by the National Institute of Arthritis and Musculoskeletal and Skin Diseases of the National Institutes of Health USA under the award number R21AR063334. We also gratefully acknowledge partial support from the Breeden Adams Foundation of Norfolk, VA, USA.

Authors declare that no conflicts of interest exist.

\section{References}

Arikawa, E., Sun, Y., Wang, J., Zhou, Q., Ning, B., Dial, S.L., et al., 2008. Cross-platform comparison of SYBR Green real-time PCR with TaqMan PCR, microarrays and other gene expression measurement technologies evaluated in the MicroArray Quality Control (MAQC) study. BMC Genomics 9, 328.

Asmar, A., Werner, A., Kelly Jr., R.E., Fecteau, A., Stacey, M., 2015. Presence and localization of pro- and mature forms of biglycan and decorin in human costal cartilage derived from chest wall deformities. Austin J. Musculoskelet. Disord. 2, 1012.

Asmar, A., Barrett-Jolley, R., Werner, A., Kelly, R.Jr., Stacey, M., 2016. Membrane channel gene expression in human costal and articular chondrocytes. Organogenesis 12, 94-107.

Barrett-Jolley, R., Lewis, R., Fallman, R., Mobasheri, A., 2010. The emerging chondrocyte channelome. Front. Physiol. 1, 135.

Bosnakovski, D., Mizuno, M., Kim, G., Ishiguro, T., Okumura, M., Iwanaga, T., et al., 2004. Chondrogenic differentiation of bovine bone marrow mesenchymal stem cells in pellet cultural system. Exp. Hematol. 32, 502-509.

Canales, R.D., Luo, Y., Willey, J.C., Austermiller, B., Barbacioru, C.C., Boysen, C., et al., 2006. Evaluation of DNA microarray results with quantitative gene expression platforms. Nat. Biotechnol. 24, 1115-1122.

Chu, X.P., Papasian, C.J., Wang, J.Q., Xiong, Z.G., 2011. Modulation of acid-sensing ion channels: molecular mechanisms and therapeutic potential. Int. J. of Physiol. Pathophysiol. Pharmacol. 3, 288-309.

Collins, J.A., Moots, R.J., Winstanley, R., Clegg, P.D., Milner, P.I., 2013. Oxygen and pHsensitivity of human osteoarthritic chondrocytes in 3-D alginate bead culture system. Osteoarthr. Cartil. 21, 1790-1798.

Creswick, H.A., Stacey, M.W., Kelly Jr., R.E., Gustin, T., Nuss, D., Harvey, H., et al., 2006. Family study of the inheritance of pectus excavatum. J. Pediatr. Surg. 41, 1699-1703.

Dascalu, A., Korenstein, R., Oron, Y., Nevo, Z., 1996. A hyperosmotic stimulus regulates intracellular $\mathrm{pH}$, calcium, and S-100 protein levels in avian chondrocytes. Biochem. Biophys. Res. Commun. 227, 368-373.

Edlich, M., Yellowley, C.E., Jacobs, C.R., Donahue, H.J., 2001. Oscillating fluid flow regulates cytosolic calcium concentration in bovine articular chondrocytes. J. Biomech. 34, 59-65.

Goretsky, M.J., Kelly Jr., R., Croitoru, D., Nuss, D., 2004. Chest wall anomalies: pectus excavatum and pectus carinatum. Adolesc. Med. 15, 455-471.

Grynkiewicz, G., Poenie, M., Tsien, R.Y., 1985. A new generation of $\mathrm{Ca}^{2+}$ indicators with greatly improved fluorescence properties. J. Biol. Chem. 260, 3440-3450.

Horth, L., Stacey, M.W., Proud, V.K., Segna, K., Rutherford, C., Nuss, D., Kelly, R.E., 2012. Advancing our understanding of the inheritance and transmission of pectus excavatum. J. Pediatr. Genet. 1, 161-173.

Hu, W., Chen, F.H., Yuan, F.L., Zhang, T.Y., Wu, F.R., Rong, C., et al., 2012. Blockade of acid-sensing ion channels protects articular chondrocytes from acid-induced apoptotic injury. Inflamm. Res. 61, 327-335.

Hu, Y.L., Mi, X., Huang, C., Wang, H.F., Song, J.R., Shu, Q., et al., 2017. Multiple $\mathrm{H}^{+}$ sensors mediate the extracellular acidification-induced $\left[\mathrm{Ca}^{2+}\right]_{\mathrm{i}}$ elevation in cultured rat ventricular cardiomyocytes. Sci. Rep. 7, 44951.

Kelly Jr., R.E., Mellins, R.B., Shamberger, R.C., Mitchell, K.K., Lawson, M.L., Oldham, K.T., et al., 2013. Multicenter study of pectus excavatum, final report: complications, static/exercise pulmonary function, and anatomic outcomes. J. Am. Coll. Surg. 217, 1080-1089.

Kurita, T., Yamamura, H., Suzuki, Y., Giles, W.R., Imaizumi, Y., 2015. The ClC-7 chloride channel is downregulated by hypoosmotic stress in human chondrocytes. Mol. Pharmacol. 88, 113-120.

Li, X., Wu, F.R., Xu, R.S., Hu, W., Jiang, D.L., Ji, C., et al., 2014. Acid-sensing ion channel 1a-mediated calcium influx regulates apoptosis of endplate chondrocytes in intervertebral discs. Expert Opin. Ther. Targets 18, 1-14.

Miaskowski, A., Gas, P., Krawczyk, A., 2016. SAR calculations for titanium bar-implant subjected to microwave radiation. In: 17th International Conference Computational Problems of Electrical Engineering (CPEE), IEEE Xplore, pp. 1-4. https://doi.org/10. 1109/CPEE.2016.7738726.

Mow, V.C., Guo, X.E., 2002. Mechano-electrochemical properties of articular cartilage: their inhomogeneities and anisotropies. Ann. Rev. Biomed. Eng. 4, 175-209.

Nuss, D., 2008. Minimally invasive surgical repair of pectus excavatum. Semin. Pediatr. Surg. 17, 209-217.

Parvizi, J., Parpura, V., Greenleaf, J.F., Bolander, M.E., 2002. Calcium signaling is required for ultrasound-stimulated aggrecan synthesis by rat chondrocytes. J. Orthop. Res. 20, 51-57.

Pilegaard, H., Licht, P.B., 2017. Minimal invasive repair of pectus excavatum and carinatum. Thorac. Surg. Clin. 27, 123-131.

Rong, C., Chen, F.H., Jiang, S., Hu, W., Wu, F.R., Chen, T.Y., et al., 2012. Inhibition of acid-sensing ion channels by amiloride protects rat articular chondrocytes from acidinduced apoptosis via a mitochondrial-mediated pathway. Cell Biol. Int. 36, 635-641.

Sanchez, J.C., Wilkins, R.J., 2004. Changes in intracellular calcium concentration in response to hypertonicity in bovine articular chondrocytes. Comp. Biochem. and Physiol. A Mol Integr. Physiol. 137, 173-182.

Sanchez, J.C., Danks, T.A., Wilkins, R.J., 2003. Mechanisms involved in the increase in intracellular calcium following hypotonic shock in bovine articular chondrocytes. Gen. Physiol. Biophys. 22, 487-500.

Semenov, I., Xiao, S., Pakhomov, A.G., 2013. Primary pathways of intracellular Ca(2+) mobilization by nanosecond pulsed electric field. Biochim. Biophys. Acta 1828, 981-989.

Stacey, M.W., Grubbs, J., Asmar, A., Pryor, J., Elsayed-Ali, H., Cao, W., et al., 2012 Decorin expression, straw-like structure, and differentiation of human costal cartilage. Connect. Tissue Res. 53, 415-421. 
Stacey, M.W., Sabuncu, A.C., Beskok, A., 2014. Dielectric characterization of costal cartilage chondrocytes. Biochim. Biophys. Acta 1840, 146-152.

Wa, Q., Gao, M., Dai, X., Yu, T., Zhou, Z., Xu, D., et al., 2015. Induction of chondrogenic differentiation of mouse embryonic mesenchymal stem cells through an in vitro pellet model. Cell Biol. Int. 39, 657-665.

Yellowley, C.E., Hancox, J.C., Donahue, H.J., 2002. Effects of cell swelling on in-

tracellular calcium and membrane currents in bovine articular chondrocytes. J. Cell. Biochem. 86, 290-301.

Yuan, F.L., Chen, F.H., Lu, W.G., Li, X., Li, J.P., Li, C.W., et al., 2010. Inhibition of acid- sensing ion channels in articular chondrocytes by amiloride attenuates articular cartilage destruction in rats with adjuvant arthritis. Inflamm. Res. 59, 939-947.

Zhang, X., Wu, Y., Pan, Z., Sun, H., Wang, J., Yu, D., et al., 2016. The effects of lactate and acid on articular chondrocytes function: implications for polymeric cartilage scaffold design. Acta Biomater. 42, 329-340.

Zhou, R., Wu, X., Wang, Z., Ge, J., Chen, F., 2015. Interleukin-6 enhances acid-induced apoptosis via upregulating acid-sensing ion channel 1a expression and function in rat articular chondrocytes. Int. Immunopharmacol. 29, 748-760. 